\title{
Generalized Competing Event Model for Cancer Risk
}

National Cancer Institute

\section{Source}

National Cancer Institute. Generalized Competing Event Model for Cancer Risk. NCI

Thesaurus. Code C137799.

A stratification method that can be used to identify groups of patients at highest risk for a poor outcome and therefore most likely to benefit from treatment intensification. 